\title{
A Newly Recognized Autosomal Recessive Syndrome Affecting Neurologic Function and Vision
}

\section{Mustafa A. Salih, ${ }^{1}$ Andreas Tzschach, ${ }^{2}$ Darren T. Oystreck, ${ }^{3 *}$ Hamdy H. Hassan, ${ }^{4}$ Abdulmajeed AIDrees, ${ }^{5}$ Salah A. Elmalik, ${ }^{5}$ Heba Y. El Khashab, ${ }^{1}$ Thomas F. Wienker, ${ }^{6}$ Khaled K. Abu-Amero, ${ }^{3}$ and Thomas M. Bosley ${ }^{3}$}

${ }^{1}$ Division of Pediatric Neurology, Department of Pediatrics, College of Medicine, King Saud University, Riyadh, Saudi Arabia

${ }^{2}$ Institut für Humangenetik, Universitätsklinikum Tübingen, Tübingen, Germany

${ }^{3}$ Department of Ophthalmology, College of Medicine, King Saud University, Riyadh, Saudi Arabia

${ }^{4}$ Department of Radiology, College of Medicine, King Saud University, Riyadh, Saudi Arabia

${ }^{5}$ Department of Physiology, College of Medicine, King Saud University, Riyadh, Saudi Arabia

${ }^{6}$ Department of Ropers-Molecular Human Genetics, Max-Planck Institute of Molecular Genetics, Berlin, Germany

Manuscript Received: 31 March 2012; Manuscript Accepted: 13 December 2012

Genetic factors represent an important etiologic group in the causation of intellectual disability. We describe a Saudi Arabian family with closley related parents in which four of six children were affected by a congenital cognitive disturbance. The four individuals (aged 18, 16, 13, and 2 years when last examined) had motor and cognitive delay with seizures in early childhood, and three of the four (sparing only the youngest child) had progressive, severe cognitive decline with spasticity. Two affected children had ocular malformations, and the three older children had progressive visual loss. The youngest had normal globes with good functional vision when last examined but exhibited the oculodigital sign, which may signify a subclinical visual deficit. A potentially deleterious nucleotide change (c.1A $>$ G; p.Met1Val) in the C12orf57 gene was homozygous in all affected individuals, heterozygous in the parents, and absent in an unaffected sibling and $>350$ normal individuals. This gene has no known function. This family manifests a autosomal recessive syndrome with some phenotypic variability that includes abnormal development of brain and eyes, delayed cognitive and motor milestones, seizures, and a severe cognitive and visual decline that is associated with a homozygous variant in a newly identified gene.

(C) 2013 Wiley Periodicals, Inc.

Key words: neurogenetic disease; intellectual disability; epilepsy; brain malformation; corpus callosum; iris coloboma; staphyloma; chorioretinal coloboma; neurodegeneration; C12orf57 gene

\section{INTRODUCTION}

Najmabadi et al. [2011] recently reported a genetic evaluation of 136 consanguineous families with presumed autosomal recessive intellectual disability using homozygosity mapping, exon enrichment, and next-generation sequencing. They found evidence of likely disease-causing genetic variants not previously associated with cognitive dysfunction in 50 families.
How to Cite this Article:

Salih MA, Tzschach A, Oystreck DT, Hassan $\mathrm{HH}$, AlDrees A, Elmalik SA, El Khashab HY, Wienker TF, Abu-Amero KK, Bosley TM. 2013. A newly recognized autosomal recessive syndrome affecting neurologic function and vision.

Am J Med Genet Part A 161A:1207-1213.

The family described here is one of the families in whom a novel variant was identified in a gene not previously thought to cause human disease (Family G001, Table II in that report). The initial report did not include the clinical details of the patients. Therefore, this report will describe in detail the phenotypes of four affected individuals in a single inbred family found to have a homozygous variant in the C12orf57 gene segregating with the syndrome [Najmabadi et al., 2011].

\section{MATERIALS AND METHODS}

The family was followed and evaluated over a period of 12 years. The father signed informed consent for a phenotype-genotype correla-

Grant sponsor: King Abdulaziz City for Science and Technology Project AT-29-31; Grant sponsor: College of Medicine Research Center Project No. $07-581$.

The authors declared they have no conflicts of interest.

${ }^{\star}$ Correspondence to:

Darren T. Oystreck, King Abdulaziz University Hospital, PO Box 245, Riyadh 11411, Saudi Arabia. E-mail: darrenoystreck@ymail.com Article first published online in Wiley Online Library

(wileyonlinelibrary.com): 30 April 2013

DOI 10.1002/ajmg.a.35850 
tion study approved by the Institutional Review Board of the College of Medicine, King Saud University, Riyadh, Saudi Arabia. This study adhered to the tenants of the Declaration of Helsinki.

The gene was identified utilizing homozygosity mapping, exon enrichment, and next-generation sequencing as described [Najmabadi et al., 2011]. Najmabadi et al. [2011] genotyped the three older siblings $(\mathrm{V}: 2, \mathrm{~V}: 3$, and $\mathrm{V}: 4)$ and three unaffected family members; the genotyping of the youngest affected family member $(\mathrm{V}: 6)$ was performed later because of delayed development.

\section{RESULTS}

\section{Clinical Evaluation}

The pedigree is shown in Figure 1. The parents of this family were second cousins and were neurologically and ophthalmologically normal. They had two unaffected children and four affected children who, when last examined, were 18 years old (Patient $\mathrm{V}: 2$ ), 16 years old (Patient V:3), 13 years old (Patient V:4), and 2 years old (Patient V:6).

\section{Patient V:2}

The proband was first examined in the Pediatric Neurology Clinic, King Khalid University Hospital, College of Medicine, King Saud University, Riyadh, at age 6 years because of psychomotor delay associated with nystagmus that had been observed at approximately 1 month of age. He was the product of an uneventful pregnancy and normal spontaneous vaginal delivery, and he had no major general medical problems except those related to vision and neurologic function. At age 9 months he had normal height $(75 \mathrm{~cm} ; 75$ th-90th centile), weight (10.4 kg; 90th centile), and head circumference

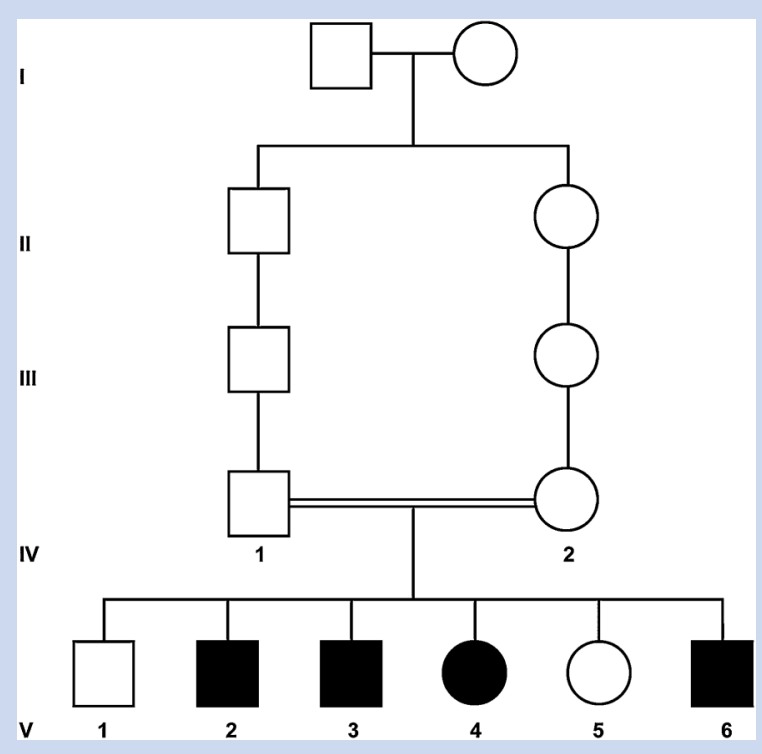

FIG. 1. Pedigree of the family described here, using standard pedigree symbols.
(47.5 cm; 90th centile). He had developed relatively normally until approximately 1 year of age, but development slowed thereafter. Formal psychological assessment at the age of 2 years noted that gross motor development was delayed to the age of 10 months and language was equivalent to that of a 7-month-old.

He began to walk at age 4 years but lost that ability at age 14 years. He developed complex partial seizures at 10 years that were partially controlled with topiramate. Functional vision was relatively good during early childhood by report but gradually declined. He had severe impairment of cognitive functioning and adaptive behavior by age 16 years, as he could not indicate basic desires, had to be fed, produced only sounds without words, and occasionally laughed inappropriately. A cranial MRI scan performed at age 15 years showed agenesis of the corpus callosum, large lateral ventricles, medial hemispheric sulci extending into the third ventricle, and periventricular gray and white matter abnormalities (Fig. 2). The left globe was small on neuroimaging with an internal appearance compatible with a complete retinal detachment (Fig. $2 \mathrm{~F}$ ). At this age, weight $(37.3 \mathrm{~kg} ; \sim 10$ th centile) was relatively lower, although head circumference remained in the normal range $(56.0 \mathrm{~cm} ; 75 \mathrm{th}-90$ th centile). His height could not be accurately measured.

On neuro-ophthalmologic examination at age 18 years, he moved all four extremities spontaneously to a small extent, but he was spastic and hypertonic throughout with diffusely increased deep tendon reflexes. He could barely stand and take a few steps with assistance because of a spastic gait. He did not interact with his environment, had to be fed, and had no verbal communication. However, formal assessment of intelligence quotient could not be performed because of his severe cognitive impairment. He would rarely fixate on an object and respond to visual threat with his right eye but not the left eye. His right pupil was sluggishly reactive to light and his left pupil was unreactive, although he had no obvious afferent pupillary defect. He was slightly enophthalmic on the left with mild ptosis. The optic disk was normal on the right. However, the right eye had an inferonasal iris coloboma (Fig. 3A) with an inferior chorioretinal coloboma and posterior staphyloma, while on the left he had microcornea with corneal scarring and a dense cataract that permitted no fundus view (Fig. 3B). Extraocular motility was grossly full with a modest esotropia. He had small amplitude horizontal pendular nystagmus in both eyes that did not change significantly on lateral gaze to either side.

\section{Patient V:3}

This boy was the product of full term pregnancy and a vacuumassisted delivery followed by an uneventful perinatal period. $\mathrm{He}$ manifested delayed development from early life, sitting unassisted at 30 months and starting to walk at 3 years. He remained stable until approximately age 5 years, when he developed complex partial seizures that were managed with carbamazepine and topiramate. At age 5 years 8 months, his height was $101 \mathrm{~cm}(\sim 5$ th centile), weight $14.5 \mathrm{~kg}(\sim 10 \mathrm{th}$ centile) and head circumference $50 \mathrm{~cm}$ (25th-50th centile). He began a long cognitive and functional decline so that by the age of 6 years language production consisted merely of sounds. He could not even indicate his desires and had to be fed by his family. However, intelligence quotient could not be 

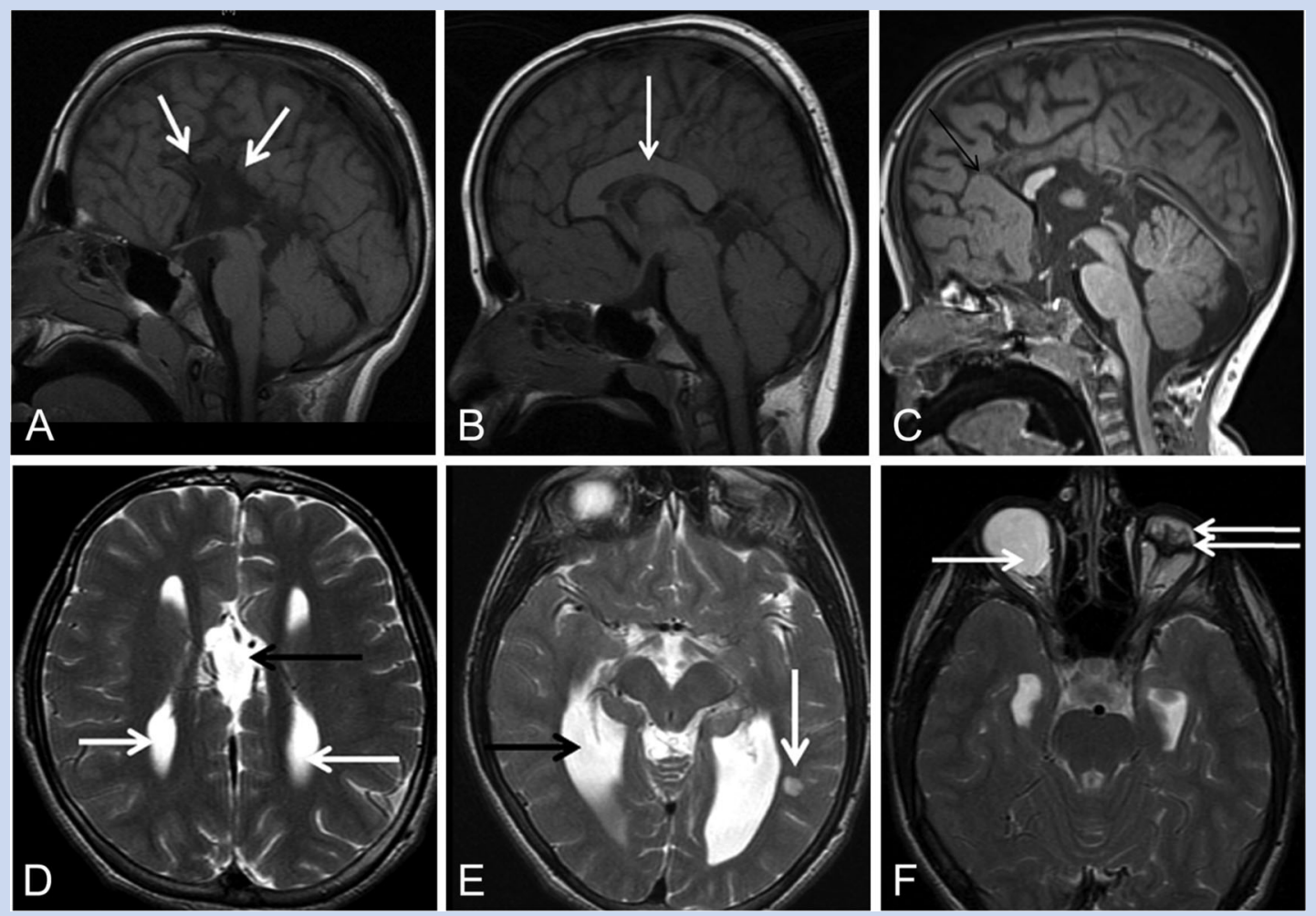

FIG. 2. Neuroimaging of the affected patients. A: A sagittal T1-weighted image [T1WI] of Patient V:2 showing agenesis of corpus callosum with medial hemispheric sulci extending into the third ventricle. B: A thick corpus callosum was visible on midline sagittal T1WI in Patient V:3, while [C] only the genu of the corpus callosum was present on sagittal T1WI [arrow) in Patient V:6; the rostrum, body and splenium were absent. D: Axial T2WI in Patient V:2 showing that the third ventricle was in continuity with the interhemispheric fissure [black arrow] and the lateral ventricles [white arrows]. E: An axial T2WI in Patient V:2 showed a small focal lesion (vertical white arrow) suggesting a hamartoma. Dilated posterior horn of lateral ventricles [colpocephaly] is indicated by black arrow. F: The axial T2WI in Patient V:2 confirming a posterior staphyloma of right eye (horizontal arrow] and phthisis bulbi on the left [double horizontal arrows] with an internal signal compatible with a total retinal detachment.

formally measured at this age because of his severe intellectual disability. He could walk with frequent tripping at that time, but by the age of 14 years he was only able to stand unassisted and walk with assistance from one room to another. Functional vision, which had been relatively good during early childhood, also gradually declined. A cranial MRI scan performed at age 13 years showed a thick corpus callosum (Fig. 2B).

On neuro-ophthalmologic examination at age 16 years, he appeared awake and minimally responsive to his environment, but he was unable to speak. Weight $(32.2 \mathrm{~kg} ; \sim 3 \mathrm{rd}$ centile) and head circumference $(52.5 \mathrm{~cm}$; 5 th-10th centile) were both relatively low. He moved all four extremities with what appeared to be grossly normal strength. He had increased tone and deep tendon reflexes throughout. He was unable to fix on or follow an object with either eye, although he responded to visual threat with both eyes. He had a small inferior chorioretinal coloboma in the right eye (Fig. 3C), while on the left he had a large posterior staphyloma (Fig. 3D), but his optic disks appeared normal on dilated examination. His extraocular motility was grossly full with a modest, comitant esotropia. He had no nystagmus and saccades appeared normal.

\section{Patient V:4}

This girl was born at full term following a normal pregnancy and delivery and had an uneventful perinatal period. Early development was relatively normal, but she never spoke. She developed focal seizures 2-3 times per day at the age of 6 months, and her first EEG showed a right-sided focus with secondary generalization. Her epilepsy was eventually relatively well controlled on topiramate, with seizures occurring 1-2 times per week. Vision and functional ability began to decline at approximately age 3 years, at which time her height was $83 \mathrm{~cm}(\sim 5$ th centile), weight $9.8 \mathrm{~kg}(\sim 3 \mathrm{rd}$ centile), and head circumference $46.5 \mathrm{~cm}$ (10th-15th centile). When assessed at almost 4 years of age, she spoke no words and could stand only with support. A cranial MRI and MR angiography at the age of 9 years showed no abnormalities.

On neuro-ophthalmologic examination at age 13 years, she was unable to sit, walk, or talk, and seemed largely unreactive to her examiners or environment. She moved all four extremities with increased tone and deep tendon reflexes throughout. She was unable to fix on or follow an object in her visual field with either eye but had a moderate response to visual threat bilaterally. Pupils 


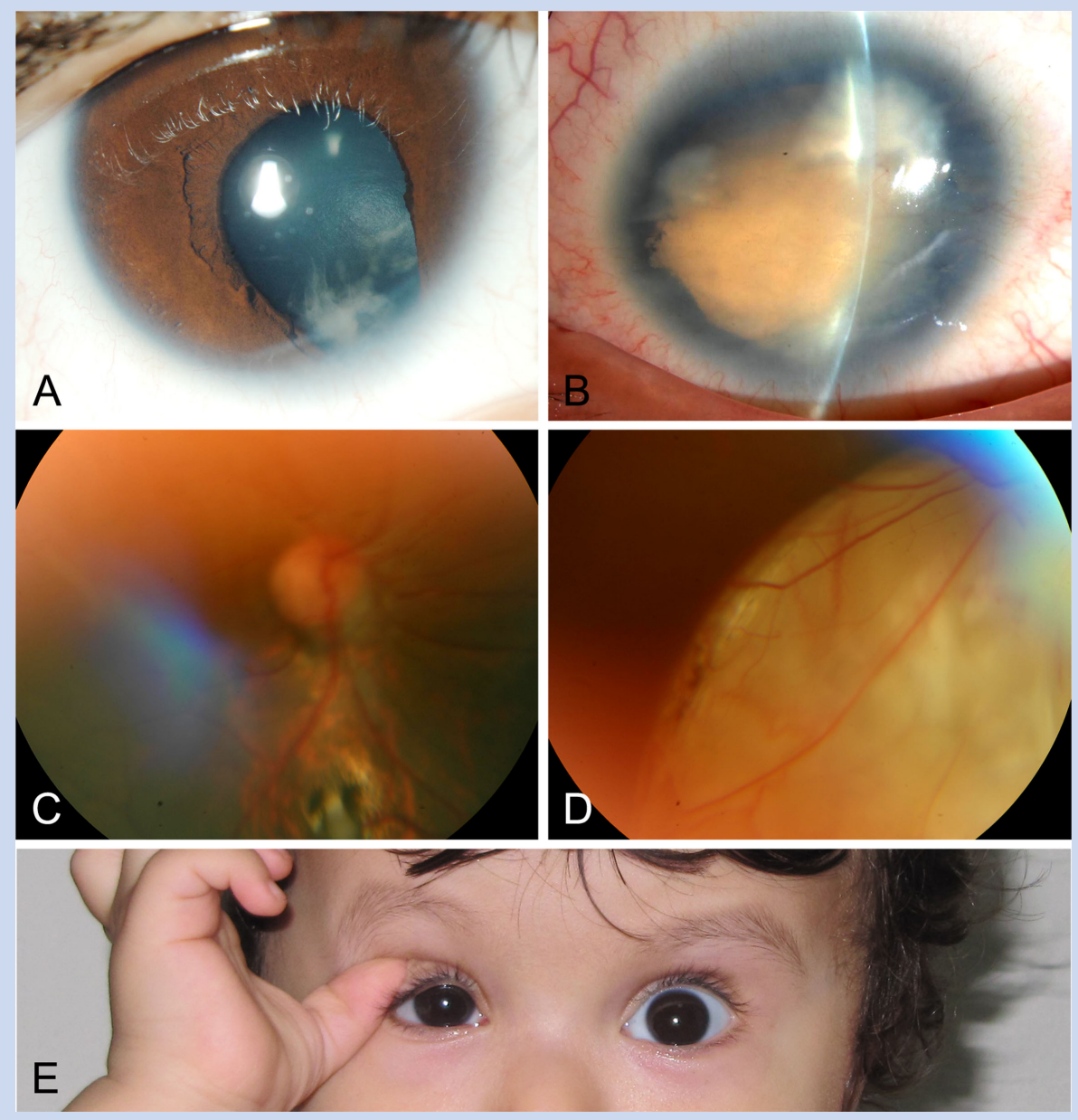

FIG. 3. Additional clinical features of affected patients. A: Patient V:2 had an inferonasal iris coloboma on the right and (B) microcornea with corneal scarring and a dense cataract in a ophthysical eye on the left. C: The fundus photos of Patient V: 3 showing an inferior chorioretinal coloboma OD and (D) a staphyloma OS. E: Patient V:6, the youngest child, had the oculodigital sign, with grossly normal afferent visual functioning, ophthalmologic examination, and ERG. [Color figure can be seen in the online version of this article, available at http://wileyonlinelibrary.com/journal/ajmga]

were normal in size and shape and reacted normally to light. Anterior globes were normal OU, and she had normal appearing optic discs and posterior poles bilaterally. Extraocular motility appeared full, and she was grossly orthophoric with no pathologic nystagmus. Saccades were normal.

\section{Patient V:6}

This boy was the product of a normal pregnancy and a normal full term spontaneous vaginal delivery with normal weight and Apgar scores. On pediatric neurology examination at the age of 1 year, he interacted well with examiner and family, but speech was confined to babbling sounds. He moved all extremities with normal tone and reflexes, but he was unable to sit or stand without assistance. Functional vision and ocular motility were grossly normal. At age 15 months his parents noted that he began to push on his right eye with one finger in a fashion typical of the oculodigital sign (Fig. 3E); however, they felt that his visual functioning remained normal bilaterally. He was admitted to hospital at the age of 2 years following his first grand mal seizure, but a thorough diagnostic evaluation at that time showed unchanged neurologic and ophthalmologic examinations. Height was $76.4 \mathrm{~cm}\left(\sim 3^{\text {rd }}\right.$ centile), weight $10.4 \mathrm{~kg}$ (25th-50th centile), and head circumference $48.0 \mathrm{~cm}$ (25th-50th centile). An EEG was normal, but cranial MRI and MR angiography (Fig. 2C) showed dysgenesis of the corpus callosum with only the genu of corpus callosum remaining but with no other obvious malformation of the brain or its vasculature.

On neuro-ophthalmologic examination at approximately age 2 years, he was alert, cooperative, and interactive with family and examiners. He moved all four extremities and showed no abnormality of tone, power, or reflex, although he was able to sit unassisted but not stand. He was visually attentive and easily able to fix on and follow objects in front of him. He responded briskly to visual threat with both eyes. Pupils were normal in size and shape and reacted normally to light. Anterior globes were 
TABLE I. History and Examination

\begin{tabular}{|c|c|c|c|c|}
\hline $\begin{array}{l}\text { Patient } \\
\text { (Pedigree No., Figure 1) }\end{array}$ & Patient V:2 & Patient V:3 & Patient V:4 & Patient V:6 \\
\hline Age at last examination & $18 y$ & $16 y$ & $13 y$ & $2 y$ \\
\hline Pregnancy & Uneventful & Uneventful & Uneventful & Uneventful \\
\hline Delivery & NSVD & $\begin{array}{c}\text { Vacuum assisted } \\
\text { delivery }\end{array}$ & NSVD & NSVD \\
\hline \multicolumn{5}{|l|}{ Developmental history } \\
\hline Gross motor & Delayed & Delayed & Delayed & Delayed \\
\hline Sitting & 36 months & 30 months & 28 months & 24 months \\
\hline Walking & 48 months & 36 months & Not yet & Not yet \\
\hline Fine motor & Delayed & Delayed & Delayed & Delayed \\
\hline Expressive language & Sounds & Sounds & Sounds & Sounds \\
\hline \multicolumn{5}{|l|}{ Seizures } \\
\hline Onset & 10 years & 5 years & 6 months & 22 months \\
\hline Type & Complex partial & Complex partial & Complex partial & Grand mal \\
\hline Treatment & Topiramate & $\begin{array}{l}\text { Carbamazepine, } \\
\text { topiramate }\end{array}$ & Topiramate & Tegretol \\
\hline $\begin{array}{l}\text { Intellectual disability/ } \\
\text { cognitive decline }\end{array}$ & Present & Present & Present & Present \\
\hline $\begin{array}{l}\text { Ophthalmologic } \\
\text { examination }\end{array}$ & $\begin{array}{l}\text { Inferonasal iris coloboma on the } \\
\text { right; chorioretinal coloboma } \\
\text { and posterior staphyloma on } \\
\text { the right; microcornea with } \\
\text { corneal opacity and dense } \\
\text { cataract on the left; } \\
\text { congenital nystagmus }\end{array}$ & $\begin{array}{l}\text { Chorioretinal } \\
\text { coloboma on the } \\
\text { right and posterior } \\
\text { staphyloma on the left }\end{array}$ & Normal & Normal \\
\hline
\end{tabular}

normal OU, and he had normal appearing optic discs and posterior poles bilaterally. Ocular motility was grossly full with no nystagmus. Saccades appeared normal.

\section{Additional Clinical Testing}

Table I summarizes clinical history and examination for all four affected individuals, while Table II details testing results, including normal results for tests related to typical causes of developmental delay. Flash visual evoked potentials (VEPs) yielded substantially prolonged P100 values on all patients even though at least Patients $\mathrm{V}: 4$ and V:6 had normal globes, normal appearing optic disks, and grossly normal afferent visual systems on neuroimaging. Electroretinograms (ERGs) done with chloral hydrate sedation using flash stimuli monocularly were normal except for mildly abnormal latencies in one eye each of Patients V:3 and V:4 and a flat ERG in the phthisical left eye of Patient $V: 2$.

\section{Genetic Results}

Utilizing exome enrichment, exon enrichment, and nextgeneration sequencing, Najmabadi et al. [2011] identified a homozygous variant (c.1A > G; p.Met1Val) uncharacterized gene (ENST00000229281) in three affected members of the family (see Table II in [Najmabadi et al., 2011]). This candidate mutation was heterozygous in the parents and not present in one unaffected sibling and 385 normal individuals. The youngest patient was subsequently documented to have the same homozygous variant after manifesting seizures. The gene is expressed mainly in the neurologic, visual, and cardiovascular systems according to the GENATLAS database (http://genatlas.medecine.univ-paris5.fr/).

Replacing methionine (Met) with valine (Val) in the initiation codon is expected to affect the translation initiation machinery [Kapp and Lorsch, 2004]. The SIFT database (http://sift.jcvi.org/) for analyzing the effect of the recognized sequence change on the protein structure and/or function predicted that this sequence change in the gene is damaging. The basic function of the C12orf57 is unknown.

\section{DISCUSSION}

This family had a syndrome inherited in an autosomal recessive pattern that included developmental abnormalities of the brain and, in some affected individuals, the eyes. All four affected children exhibited delayed motor and cognitive milestones, with walking occurring after the age of 3 years and speech never achieved in the three older children. Each child developed seizures during early childhood, and the three older children also had a progressive loss of functional ability beginning at 3-5 years with diffuse spasticity and poor interaction with the environment by the teenage years. Three of the children $(\mathrm{V}: 2, \mathrm{~V}: 3$, and $\mathrm{V}: 6)$ had malformations of the corpus callosum (Fig. 2), while the two oldest boys (V:2 and V:3) also had malformations of the globes (Fig. 3). Interestingly, the third child (V:4) had normal globes and a normal cranial MRI scan despite 
TABLE II. Investigations

\begin{tabular}{|c|c|c|}
\hline & Patient V:2 & Patient V:3 \\
\hline Blood tandem MS & Unremarkable & Unremarkable \\
\hline Urine GC/MS & Unremarkable & Unremarkable \\
\hline $\begin{array}{l}\text { High resolution } \\
\text { karyotyping }\end{array}$ & $46, X Y$ & $46, X Y$ \\
\hline TORCH screening & Negative & Negative \\
\hline Anthropometry & $\begin{array}{l}\text { Weight, height, and } \\
\text { head circumference } \\
<5 \text { th centile }\end{array}$ & $\begin{array}{l}\text { Head circumference } \\
2 \text { SD below mean; } \\
\text { weight and height } \\
<5 \text { th centile }\end{array}$ \\
\hline EEG & $\begin{array}{l}\text { Slow background on right; } \\
\text { frequent spikes and } \\
\text { spike-wave discharges } \\
\text { predominantly in right } \\
\text { temporal region }\end{array}$ & Posterior slowing \\
\hline BAER & Normal & Normal \\
\hline \multirow[t]{2}{*}{ VEP } & $\begin{array}{l}\text { OD, delayed P100 latency } \\
\text { [179 msec }]\end{array}$ & $\begin{array}{l}\text { OD, delayed P100 latency } \\
\text { (140 msec }]\end{array}$ \\
\hline & $\begin{array}{l}\text { OS, no reproducible } \\
\text { response }\end{array}$ & $\begin{array}{l}\text { OS, delayed P100 latency } \\
\text { (136 msec }]\end{array}$ \\
\hline \multirow[t]{2}{*}{ ERG } & OD, within normal limits & OD, within normal limits \\
\hline & $\begin{array}{l}\text { OS, no reproducible } \\
\text { response }\end{array}$ & $\begin{array}{l}\text { OS, delayed latencies of } \\
\text { "a" and "b" waves }\end{array}$ \\
\hline MRI & $\begin{array}{l}\text { Agenesis of corpus } \\
\text { callosum; colpocephaly; } \\
\text { small low density areas } \\
\text { in the subcortical white } \\
\text { matter on left }\end{array}$ & $\begin{array}{l}\text { Thickened corpus } \\
\text { callosum }\end{array}$ \\
\hline
\end{tabular}

\begin{tabular}{ll}
\multicolumn{1}{c}{ Patient V:4 } & \multicolumn{1}{c}{ Patient V:6 } \\
Unremarkable & Unremarkable \\
Unremarkable & Unremarkable \\
$46, X X$ & $46, X Y$
\end{tabular}

\section{Negative}

Head circumference

2 SD below mean;

weight and height

$<5$ th centile

Generalized back-ground

slowing; multifocal

epileptiform activity

indicating bilateral

fronto-temporal foci

Normal

OD, delayed P100 latency

(177 msec)

OS, delayed P100 latency

(175 msec)

$\mathrm{OD}$, delayed latencies of

"a" and "b" waves

OS, within normal limits

Unremarkable

\section{Not done}

Height and weight

$<5$ th centile

Normal awake study

Normal

OD, delayed P100 latency

(190 msec)

OS, delayed P100 latency

(189 $\mathrm{msec}$ )

OU, within normal limits

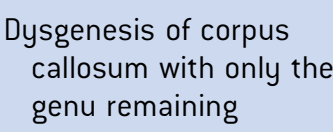

BAER, brainstem auditory evoked potentials; VEP, flash visual evoked potentials; ERG, electroretinogram; MRI, magnetic resonance imaging; OD, right; OS, left; OU, both eyes; $y$, years.

developmental delay, seizures, and a progressive, severe cognitive and visual decline, indicating that brain and eye malformations are not necessary for the neurodegenerative component of the syndrome.

All four children were felt by their parents to have relatively normal vision during early childhood; however, vision declined after age 3-5 years along with cognitive function. The three oldest patients each had very poor functional vision when last examined at ages 18,16 , and 13 years, but the youngest patient had grossly normal vision at age 2 years. None had retinal pigmentary changes, and ERGs were normal in at least one eye of all affected individuals. The oldest boy (V:2) had clinically reduced vision in both eyes from early childhood, likely related to his iris and chorioretinal colobomas on the right and at least microcornea on the left, with congenital nystagmus noted during infancy. He had a blind, phthisical eye on the left when first examined ophthalmologically, quite likely secondary to a total retinal detachment associated with the developmental abnormality of that globe. Patient V:3 also had developmental abnormalities of both globes (chorioretinal coloboma on the right and posterior staphyloma on the left) but no ocular or funduscopic changes that explained progressive visual loss. The third child (V:4) was unable to fix and follow when examined at age 13 years despite normal globes and fundi. Only the youngest child
(V:6) had normal functional vision, although he had the oculodigital sign (see Fig. 3E) that may be a sign of visual impairment not yet clinically apparent. All four children had very delayed VEPs that quite likely imply involvement of the afferent visual system by the same progressive brain abnormality affecting cognitive function, although curiously this problem is not reflected in neuroimaging, ophthalmologic examination, or ERG.

The major phenotypic features of the present family include developmental abnormalities of the brain and eye with a progressive neurodegenerative process profoundly affecting both cognitive and visual function. The eye malformations included congenital colobomata, which can be seen in an array of syndromes where the ocular phenotype is associated with neurologic or craniofacial anomalies or developmental defects of other systems [GregoryEvans et al., 2004]. Within the autosomal recessive disorders, several of the features in the present family are shared with the Peters-plus syndrome (OMIM \# 261540) caused by B3GALTL gene mutation [Reis et al., 2008; Aliferis et al., 2010; Bhandari et al., 2011] including ocular colobomas and brain developmental abnormalities that include mental retardation, seizures, and agenesis of the corpus callosum. However, patients with Peters-plus syndrome have characteristic dysmorphic features such as widely spaced eyes, upslanting palpebral fissures, thin vermilion border, cupid-bow 
shaped upper lip, and cleft lip and palate, none of which were apparent in this family. Moreover, patients with Peters-plus anomaly have rhizomelic short stature in addition to cardiac and/or genito-urinary anomalies, none of which were identified in the present family.

Three of the dystroglycanopathies also feature significant ocular malformations associated with intellectual disability and/or epilepsy. These include Walker-Warburg syndrome [Manzini et al., 2008, 2012], muscle-eye-brain disease [Diesen et al., 2004], and Fukuyama congenital muscular dystrophy [Yoshioka, 2009]. Each of these disorders has retinal colobomas in common with the present family. However, these three conditions are also associated with congenital muscular dystrophy and with abnormalities in neuronal migration (cobblestone lissencephaly or polymicrogyria) and dysplasia of the cerebellum (hypoplasia, cysts and/or polymicrogyria), none of which were present in the family reported here.

Another similar recessively inherited disease is congenital disorder of glycosylation type 1q (OMIM \# 612379) caused by SRD5A3 mutation [Cantagrel et al., 2010]. This is characterized by colobomas and variable visual loss associated with developmental delay and cognitive impairment. However patients have, in contrast to the present cohort, characteristic dysmorphic features including widely spaced eyes, depressed nasal bridge, low-set ears, loose skin, and brachycephaly. They also have ichthiosiform dermatitis and endocrine abnormalities [Al-Gazali et al., 2008], and manifest abnormalities in neuronal migration (frontal polymicrogyria) and cerebellar vermis hypoplasia, which were not seen in the present family.

The four affected members of this family may well represent a newly recognized progressive neurodegenerative syndrome with modest phenotypic variability that is likely to be inherited in an autosomal recessive pattern. These individuals all had a homozygous variant of C12orf57 in which the initial methionine was changed to a valine [Najmabadi et al., 2011], an alteration that is predicted to affect both the expression of the gene and the action of the resultant protein [Kapp and Lorsch, 2004]. We hypothesize that this variant may explain the phenotype in these four patients, although confirmatory data are needed to prove that it is causal. The function of C12orf57 is not currently known [Najmabadi et al., 2011], but the phenotype in this family may imply that it is important to developing and maintaining the brain and eyes. Identification of a likely responsible gene in only one affected family is a testimony to the power of next generation sequencing, but obviously additional affected patients and families must be identified to confirm the pathogenicity of C12orf57 and to further characterize both the clinical syndrome and the function of the gene.

\section{ACKNOWLEDGMENTS}

This work was supported in part by the King Abdulaziz City for Science and Technology [Project AT-29-31]. MAS was also supported in part by College of Medicine Research Center (Project No.
07-581), College of Medicine, King Saud University, Riyadh, Saudi Arabia.

\section{REFERENCES}

Al-Gazali L, Hertecant J, Algawi K, El Teraifi H, Dattani M. 2008. A new autosomal recessive syndrome of ocular colobomas, ichthyosis, brain malformations and endocrine abnormalities in an inbred Emirati family. Am J Med Genet Part A 146A:813-819.

Aliferis K, Marsal C, Pelletier V, Doray B, Weiss MM, Tops CM, SpeegSchatz C, Lesnik SA, Dollfus H. 2010. A novel nonsense B3GALTL mutation confirms Peters plus syndrome in a patient with multiple malformations and Peters anomaly. Ophthal Genet 31:205-208.

Bhandari R, Ferri S, Whittaker B, Liu M, Lazzaro DR. 2011. Peters anomaly: Review of the literature. Cornea 30:939-944.

Cantagrel V, Lefeber DJ, Ng BG, Guan Z, Silhavy JL, Bielas SL, Lehle L, Hombauer H, Adamowicz M, Swiezewska E, De Brouwer AP, Blumel P, Sykut-Cegielska J, Houliston S, Swistun D, Ali BR, Dobyns WB, BabovicVuksanovic D, van Bokhoven H, Wevers RA, Raetz CR, Freeze HH, Morava E, Al-Gazali L, Gleeson JG. 2010. SRD5A3 is required for converting polyprenol to dolichol and is mutated in a congenital glycosylation disorder. Cell 142:203-217.

Diesen C, Saarinen A, Pihko H, Rosenlew C, Cormand B, Dobyns WB, Dieguez J, Valanne L, Joensuu T, Lehesjoki AE. 2004. POMGnT1 mutation and phenotypic spectrum in muscle-eye-brain disease. J Med Genet 41:e115.

Gregory-Evans CY, Williams MJ, Halford S, Gregory-Evans K. 2004. Ocular coloboma: A reassessment in the age of molecular neuroscience. J Med Genet 41:881-891.

Kapp LD, Lorsch JR. 2004. The molecular mechanics of eukaryotic translation. Annu Rev Biochem 73:657-704.

Manzini MC, Gleason D, Chang BS, Hill RS, Barry BJ, Partlow JN, Poduri A, Currier S, Galvin-Parton P, Shapiro LR, Schmidt K, Davis JG, BaselVanagaite L, Seidahmed MZ, Salih MA, Dobyns WB, Walsh CA. 2008. Ethnically diverse causes of Walker-Warburg syndrome (WWS): FCMD mutations are a more common cause of WWS outside of the Middle East. Hum Mutat 29:E231-E241.

Manzini MC, Tambunan DE, Hill RS, Yu TW, Maynard TM, Heinzen EL, Shianna KV, Stevens CR, Partlow JN, Barry BJ, Rodriguez J, Gupta VA, Al-Qudah AK, Eyaid WM, Friedman JM, Salih MA, Clark R, Moroni I, Mora M, Beggs AH, Gabriel SB, Walsh CA. 2012. Exome sequencing and functional validation in zebrafish identify GTDC2 mutations as a cause of Walker-Warburg syndrome. Am J Med Genet 91:541-547.

Najmabadi H, Hu H, Garshasbi M, Zemojtel T, Abedini SS, Chen W, Hosseini M, Behjati F, Haas S, Jamali P, Zecha A, Mohseni M, Puttmann L, Vahid LN, Jensen C, Moheb LA, Bienek M, Larti F, Mueller I, Weissmann R, Darvish H, Wrogemann K, Hadavi V, Lipkowitz B, Esmaeeli-Nieh S, Wieczorek D, Kariminejad R, Firouzabadi SG, Cohen M, Fattahi Z, Rost I, Mojahedi F, Hertzberg C, Dehghan A, Rajab A, Banavandi MJ, Hoffer J, Falah M, Musante L, Kalscheuer V, Ullmann R, Kuss AW, Tzschach A, Kahrizi K, Ropers HH. 2011. Deep sequencing reveals 50 novel genes for recessive cognitive disorders. Nature 478:57-63.

Reis LM, Tyler RC, Abdul-Rahman O, Trapane P, Wallerstein R, Broome D, Hoffman J, Khan A, Paradiso C, Ron N, Bergner A, Semina EV. 2008. Mutation analysis of B3GALTL in Peters Plus syndrome. Am J Med Genet Part A 146A:2603-2610.

Yoshioka M. 2009. Phenotypic spectrum of Fukutinopathy: Most severe phenotype of Fukutinopathy. Brain Dev 31:419-422. 